\title{
O BRINCAR DE CRIANÇAS ESCOLARES NA BRINQUEDOTECA
}

\section{SCHOOLCHILDREN'S PLAY BEHAVIOR IN THE TOY LIBRARY}

Samira M. Macarini"

Mauro L. Vieira**

\begin{abstract}
Macarini SM, Vieira ML. O brincar de crianças escolares na brinquedoteca. Rev Bras
Crescimento Desenvolv Hum. 2006;16(1):49-60.
\end{abstract}

\begin{abstract}
Resumo: A presente pesquisa teve como objetivo caracterizar o ato de brincar de crianças escolares em uma brinquedoteca; identificando os diferentes brinquedos mais utilizados entre meninos e meninas na brincadeira. Foram realizadas 517 observações diretas de eventos de brincadeira livre, utilizando-se um protocolo de observação. Os resultados confirmaram a existência de segregação e estereotipia no brincar infantil, mostrando que meninos tendem a brincar entre si e meninas também. Foi evidenciado que a composição do grupo, de acordo com o sexo das crianças, determina o tipo de brinquedo utilizado na atividade lúdica. Com relação aos grupos de meninos, foi verificada preferência pelos jogos sociais, brinquedos que reproduzem o mundo técnico - miniaturas, carrinhos, helicópteros - e fantasias. Nos grupos de meninas, constatou-se predominância por brinquedos responsáveis pelo desenvolvimento afetivo - bonecas, bebês, roupinhas - jogos sociais e fantasias. Nos grupos mistos verificou-se uma predominância da utilização dos jogos sociais, das fantasias e dos brinquedos que reproduzem o mundo técnico. A variedade de brincadeiras verificada pode ser remetida ao grande acervo de brinquedos e possibilidades de criações propiciadas pelos diferentes espaços lúdicos da brinquedoteca.
\end{abstract}

Palavras-chave: brincadeira, brinquedoteca, gênero.

\section{INTRODUÇ̃̃O}

O ser humano necessita do contato com outras pessoas, pois é através da interação social que se desenvolve a linguagem, são reconhecidas as habilidades e são ampliados os conhecimentos em diferentes áreas. Para a criança, o contato físico, o social e a comunicação são fundamentais no seu desenvolvimento e uma das maneiras mais eficazes para ela estabelecer estes contatos é através da brincadeira ${ }^{1}$.

Ao falar sobre a importância do brincar, é necessário definir tal conceito, diferenciandoo de outras formas de comportamento. No entanto isso nem sempre é possível, visto que o brincar é um comportamento complexo e suas definições são, muitas vezes, insuficientes ${ }^{2}$. De acordo com Kishimoto ${ }^{3}$, a brincadeira possui um fim em si mesma, ou seja, surge livre, sem noção de obrigatoriedade, exercendo-se pelo simples prazer que a criança encontra ao colocá-la em prática.

As crianças possuem diversas razões para brincar, sendo uma delas o próprio prazer que podem usufruir enquanto brincam. No entanto, é importante salientar que a brincadeira possui um lugar fundamental no desenvolvimento infantil. A importância da brinca-

\footnotetext{
Acadêmica do curso de Psicologia da Universidade Federal de Santa Catarina e bolsista de Iniciação Cientifica (PIBIC/ CNPq/UFSC). E-mail: samiramacarini@gmail.com

** Psicólogo, Doutor em Psicologia pela Universidade de São Paulo e Pós-Doutorado pela Dalhousie University, Canadá. Professor Adjunto do Departamento de Psicologia da Universidade Federal de Santa Catarina. Endereço: Dpto de Psicologia UFSC Campus Universitário - Trindade. CEP: 88040-900. Florianópolis-SC. E-mail: mvieira@ cfh.ufsc.br
} 
deira pode estar relacionada com a possibilidade de fornecer à criança um ambiente planejado e enriquecido que propicie a aprendizagem de várias atividades ${ }^{4}$. Além disso, a brincadeira está ligada também aos aspectos do desenvolvimento físico, cognitivo, social e afetivo 5 .

Com relação ao aspecto físico, algumas brincadeiras propiciam o desenvolvimento de habilidades como a força, a agilidade, a destreza, a psicomotricidade fina, etc ${ }^{6}$. Podem-se destacar, também, benefícios da brincadeira relacionados ao desenvolvimento cognitivo, citados por Moraes ${ }^{4}$ : a capacidade de concentração, o desenvolvimento da lógica e da linguagem. Esse tipo de brincadeira que, geralmente, envolve números, charadas, utiliza o raciocínio lógico, o pensamento abstrato, rapidez de raciocínio e, ao mesmo tempo, é combinada com atividades que requeiram ação, entusiasmam as crianças ${ }^{6}$.

A brincadeira, ainda, contribui de forma bastante efetiva para o relacionamento social das crianças, visto que oferece uma forma livre e autônoma de interação entre as mesmas. Através dela, a criança é capaz de resgatar valores e sentimentos que são importantes para a vida adulta, como a responsabilidade, além aprender a importância da negociação, da conquista, de conviver com regras e a resolver conflitos ${ }^{4}$.

Por fim, o aspecto afetivo da brincadeira encontra-se na possibilidade que ela oferece de a criança se conhecer melhor tendo, assim, oportunidades de encontrar nos outros atitudes e habilidades que causem admiração, que combinem com sua maneira de pensar, que causem vontade de conhecer melhor o outro, emergindo daí as primeiras amizades ${ }^{6}$. Através das brincadeiras as crianças podem exprimir a sua agressividade, dominar suas angústias e trabalhar a ansiedade ${ }^{7,8}$.

A atividade durante o brincar exige da criança um relativo consumo de tempo e ener- gia. Apesar disso, seus benefícios superam os gastos, transformando-se em investimento ${ }^{9,2}$. Estes benefícios podem manifestar-se de forma imediata ou de longo prazo no decorrer do desenvolvimento do indivíduo como, por exemplo, o treino para atividades e habilidades que serão úteis na vida adulta tais como: ser mãe ou pai, trabalhar ou constituir famíliai ${ }^{10}$.

\section{O brincar e as diferenças de gênero}

No brincar infantil existem diferenças de gênero, as quais podem ser verificadas em diversas espécies, inclusive nos seres huma$\operatorname{nos}^{11}$. A criança começa a demonstrar preferências sexualmente estereotipadas próximo aos 18 meses de idade $^{12}$. No entanto, antes mesmo disso, elas já são capazes de mostrar certa estereotipia demonstrando preferência por brinquedos relacionados ao seu gênero ${ }^{13}$. Os meninos preferem o brincar turbulento como pular, rolar e lutar; enquanto que as meninas, geralmente brincam com temas relacionados ao lar'. Este fato também foi verificado em pesquisa realizada por Lindsey e $\mathrm{Mize}^{14}$, os quais constataram, por meio de observação de sessões de brincadeira livre em crianças pré-escolares, que as meninas engajam-se mais no faz-de-conta, ao passo que os meninos preferem o brincar que envolve atividade física.

Alguns brinquedos são classificados por adultos e crianças como próprios do universo feminino ou do masculino. O espaço familiar da casa é associado às meninas, enquanto que o universo externo e do trabalho aos meninos ${ }^{15}$. Estes dados estão de acordo com Bichara ${ }^{16}$ quando a autora aponta que as meninas procuram por brincadeiras que imitam a vida real, como atividades domésticas, casamentos e festas; enquanto que os meninos preferem os modelos fantásticos como brincadeiras de superherói, papéis com muita ação e transportes (carro, avião). 
Em termos empíricos, pesquisas têm sido realizadas com o objetivo de verificar quais tipos de brinquedos são mais utilizados pelos meninos e pelas meninas. Um estudo realizado com crianças de 4 a 6 anos de idade, o qual utilizou três escalas - uma de brincadeiras de meninas, uma de meninos e uma neutra - respondidas pelas mães, verificou que os meninos apresentaram maior escore na escala de brincadeiras masculinas enquanto que as meninas pontuaram mais na escala feminina ${ }^{17}$.

Em outra pesquisa ${ }^{18}$, utilizando observações diretas de brincadeira livre entre mãe e filho, foram encontrados resultados semelhantes ao estudo anterior. Participaram crianças de 9 e 14 meses e foi verificado que meninas brincaram mais com brinquedos femininos do que masculinos, enquanto meninos utilizaram mais os brinquedos masculinos do que os femininos nas interações lúdicas. Servin, Bohlin e Berlin ${ }^{19}$ em seu estudo que objetivou investigar a escolha de brinquedos por crianças de 1,3 e 5 anos de idade em sessões estruturadas de brincadeira, também verificaram que meninos possuem preferência pelos brinquedos masculinos, e meninas pelos femininos.

Com relação à estereotipia na brincadeira de meninos e meninas, Servin e cols. ${ }^{19}$ constataram que meninas tornam-se progressivamente menos envolvidas com brinquedos femininos e mais com masculinos ao longo da idade, embora em proporções diferenciadas. No caso dos meninos, os autores verificaram que a preferência deles por brinquedos femininos decresce ao longo da idade, enquanto que a utilização dos brinquedos masculinos cresce até os cinco anos e, após isso, diminui. Outros estudos, realizados através de observação de brincadeira livre, também verificaram que os meninos brincam de maneira mais estereotipada do que as meninas ${ }^{7,20}$. Os resultados de algumas pesquisas, no entanto, têm se mostrado contra- ditórios, indicando que meninas possuem maior estereotipia de gênero na brincadeira do que os meninos $^{21,22}$.

Durante a brincadeira, as crianças começam a fazer distinções quanto ao papel de gênero imposto pela sociedade e cultura onde estão inseridas ${ }^{9}$. Por volta dos seis e sete anos de idade, as crianças já apresentam um conhecimento sobre as atividades, papéis sexuais e objetos sexualmente tipificados e brincam de maneira segregada, ou seja, em grupos separados de meninos e meninas ${ }^{23}$. O brincar estereotipado, segundo Liss ${ }^{24}$, traz como consequiência, em função de meninos e meninas socializarem-se dentro de diferentes mundos, a aquisição de habilidades distintas.

Fabes, Martin e Hanish ${ }^{25}$, por meio de observações diretas de brincadeira livre, examinaram o brincar em função do sexo e da composição do grupo das crianças durante a brincadeira. Os autores verificaram que apenas $25 \%$ das interações envolviam crianças de ambos os sexos, sendo que estas eram mais propensas o ocorrerem perto de adultos. $\mathrm{O}$ restante, ou seja, $75 \%$ das brincadeiras ocorriam entre crianças de mesmo sexo. Um outro estudo, realizado com crianças de 3 a 7 anos de idade, constatou que entre 6 e 7 anos a segregação dos sexos nas brincadeiras é maior $^{23}$.

A partir de uma concepção interacionista, pode-se explicar as diferenças de gênero com base na interdependência dos aspectos filogenéticos e culturais do desenvolvimento humano. Essas diferenças teriam sido consolidadas no ambiente de adaptação da espécie; ou seja, é possível que o ambiente em que viveram os ancestrais tenha dotado homens e mulheres de propensões comportamentais diferentes $^{26}$. Tais propensões estariam ligadas a sistemas de crenças e valores que são estabelecidos culturalmente ${ }^{27}$.

Diante do exposto, pode-se dizer que o brincar é um comportamento característico da 
infância, sendo que pode variar de acordo com o sexo da criança. Além disso, outros fatores podem influenciar e modificar o brincar infantil, tais como a idade da criança, a presença de objetos lúdicos e o ambiente físico em que ocorre a brincadeira ${ }^{28}$. Especificamente com relação a este último, o brincar pode ocorrer em diversos locais, sendo estes abertos, fechados, estruturados ou não.

\section{A brinquedoteca}

A brinquedoteca é um espaço estruturado para estimular a criança a brincar, possibilitando o acesso a uma grande variedade de brinquedos, dentro de um ambiente especialmente lúdico. Sendo um local propício para estimular a criatividade, é preparada de forma que seus espaços incentivem a brincadeira de 'faz-de-conta', a dramatização, a construção, a solução de problemas, a socialização e o desejo de inventar. Tem como objetivos, entre outros: a) valorizar os brinquedos e as atividades lúdicas e criativas, dando-lhes a devida importância; b) possibilitar o acesso e empréstimo de brinquedos; c) dar orientações sobre adequação e utilização dos mesmos; d) ajudar a criança a desvincular o brinquedo de seu aspecto de posse e consumo; e e)estimular o desenvolvimento de habilidades físicas, cognitivas, sociais e afetivas ${ }^{29}$.

Diante da relevância do brincar, com a necessidade de proporcionar uma educação integral à criança, verifica-se a necessidade de estudos sobre o brincar na brinquedoteca, um local com grande acervo de brinquedos possibilitando uma ampla possibilidade de atividades para as crianças. Com base nesses pressupostos, a presente pesquisa teve como objetivo principal caracterizar o ato de brincar de crianças escolares em uma brinquedoteca, identificando os brinquedos mais utilizados e as diferenças de gênero existentes na brincadeira.

\section{MÉTODO}

\section{Participantes}

Participaram desta pesquisa crianças, com idades entre 6 e 8 anos, matriculadas em uma escola pública associada à Universidade Federal de Santa Catarina. Dentro da instituição de Ensino Fundamental e Médio há uma brinquedoteca onde as crianças de $1^{2}$ a $4^{a}$ série (Ensino Fundamental) utilizam-se do espaço e dos brinquedos livremente. Dessa população foram observadas brincadeiras de crianças matriculadas nas $1^{\text {as }} \mathrm{e} 2^{\text {as }}$ séries, totalizando em torno de 150 crianças. As turmas freqüentam o espaço uma vez por semana em horário curricular, sendo destinados quarenta e cinco minutos para cada metade da turma (aproximadamente 15 crianças) na brinquedoteca.

\section{Caracterização da brinquedoteca}

O espaço da brinquedoteca possui forma retangular, em torno de $25 \mathrm{~m}^{2}$. Para fins de observação, o espaço lúdico foi dividido em quatro áreas, as quais são descritas tendo como referência a entrada pela cortina:

1 -tapete: localiza-se no centro da sala e possui forma retangular. Sobre ele existem algumas almofadas em forma de animais. Ao lado esquerdo do tapete, encontra-se um painel móvel de tecido, suspenso com fios de aço, com bolsos nos quais guardam-se livros.

2 - espaço da parede: localiza-se logo após o tapete. Na parede existe uma lousa e estão dispostos alguns brinquedos, como carrinhos de boneca e supermercado, bonecas, berço, mesinha, mini fogão e tapete de letras (logo abaixo da lousa). No canto direito existe uma estrutura em formato de cabana, que pode tanto se transformar em casinha quanto em circo. Em vista da dificuldade de observar eventos de 
brincadeiras dentro desse espaço fechado, os mesmos não foram observados.

3- mesinha: localiza-se à direita do tapete, entre a casinha e o canto da beleza (que será descrito a seguir). Em volta da mesma, estão dispostos bancos de material reciclado e tecido.

4- canto da beleza: neste espaço estão dispostos dois espelhos, um baú, um cabideiro e uma mesinha. O baú e o cabideiro são utilizados para guardar fantasias, sendo que o último tambémé utilizado para limitar o espaço do canto da beleza.

Além desses quatro espaços, localizamse, na parede esquerda, cinco prateleiras onde são guardados os diversos tipos de brinquedos. A fim de facilitar a identificação visual, tanto pelas crianças como pelos adultos, os brinquedos na brinquedoteca são divididos segundo uma classificação elaborada pelo International Council of Children's Play (ICCP). Tal instrumento facilitador das atividades dos profissionais encarregados de escolher o material de jogo para as coletividades de crianças, em diversas ocasiões, serve para analisar os brinquedos a fim de melhorar tal escolha e para melhor compreender a criança que brinca ${ }^{30}$. As sete classificações, nas quais o presente estudo se baseia, são as seguintes:

Vermelho: brinquedos para primeira idade e para atividades sensório-motoras - brinquedos como quadros de atividades com peças coloridas, de formas diversas; brinquedos para empurrar, puxar, rolar; bolas e cubos em tecido; formas para empilhar; miçangas para enfiar em cordão; brinquedos para martelar, caixas de música.

Azul escuro: brinquedos para atividades físicas - brinquedos como bolas, petecas, cordas, boliches, jogo de argolas, peças para atirar em alvo.

Amarelo: brinquedos para atividades intelectuais - brinquedos como quebra-cabeças; brinquedos de montar por superposição ou encaixe; materiais didáticos como papel, lápis, livros; jogos pedagógicos.

Verde: brinquedos que reproduzem o mundo técnico - brinquedos como veículos, bonecos e aparelhos em miniatura; objetos transformáveis, robôs.

Rosa: brinquedos para o desenvolvimento afetivo - brinquedos como pelúcia, bonecas, bebês, acessórios para bonecas (roupas, bijuterias), louças, panelinhas, fogões, miniaturas de figuras (animais), acessórios de beleza (maquiagem, bolsas, bijuterias).

Azul claro: brinquedos para atividades criativas - brinquedos como almofadas criativas, instrumentos musicais, mosaicos, dobraduras, fantoches, carimbos.

Cinza: brinquedos para relações sociais - jogos de carta, de estratégia, de percurso, de interpretação, entre outros.

Além destas categorias por famílias de brinquedos formuladas pela ICCP, foi criada, para o presente estudo, uma nova categoria denominada fantasia, a qual abrange roupas de carnaval, super-herói, palhaço, bichos, personagens infantis, máscaras, vestidos, chapeis, perucas, bijuterias, entre outros.

\section{Procedimentos}

Após o projeto ter sido aprovado pelo Comitê de Ética em Pesquisas com Seres Humanos (163/04), foram realizadas observações diretas de eventos de brincadeira livre utilizando-se um protocolo de observação construído pelos pesquisadores. Os eventos de brincadeira foram observados nos quatro espaços da brinquedoteca descritos anteriormente. Os pesquisadores observavam por quinze segundos os eventos de brincadeira num local e depois registravam durante os próximos quinze segundos. A ordem de observação foi a seguinte: primeiro no espaço 1 (tapete), em seguida no es- 
paço 2 (espaço da parede), no espaço 3 (mesinha) e por fim no espaço 4 (canto da beleza), retornando novamente ao espaço 1. Esta ordem era seguida até que o tempo de permanência das crianças na brinquedoteca se esgotasse. No total foram registrados 517 eventos de brincadeira.

Para determinar a fidedignidade da coleta de dados, uma etapa inicial foi realizada com dois observadores, que registraram independentemente os 100 primeiros eventos de brincadeira. Procurou-se obter no mínimo $70 \%$ de concordância em relação ao registro dos dados, índice que se encontra na literatura sobre observação e registro de comportamento ${ }^{31}$.

Este estudo observacional fundamenta a possibilidade de descrição e compreensão do funcionamento da brinquedoteca, além da identificação de aspectos presentes na brincadeira, revelando detalhes do fenômeno. Segundo Pellegrini ${ }^{32}$, estudos observacionais em ambientes cotidianos, de caráter exploratório e descritivo, devem ser valorizados permitem que os fenômenos possam ser melhor conhecidos. A vantagem da utilização de um método de observação naturalístico é a captura do comportamento da criança em seu ambiente, sendo desvantajoso apenas quando se deseja estudar comportamentos raros ou privados ${ }^{33}$.

\section{Análise dos dados}

Após a coleta dos dados, esses foram lançados em uma planilha do programa estatístico SPSS (versão 11.5). Através deste foi possível realizar análises estatísticas descritivas, principalmente porcentagens, e testes de associação qui-quadrado, o qual permite testar a significância da associação entre duas variáveis qualitativas. Foram considerados significantes apenas os resultados estatísticos com grau de probabilidade igual ou superior a $95 \%$.

\section{RESULTADOS}

\section{Caracterização dos eventos de brincadeira quanto ao sexo das crianças}

Os eventos foram classificados em três grupos, de acordo com o sexo das crianças presentes no evento de brincadeira: a) eventos de meninos, onde havia a presença de um ou mais meninos; b) eventos de meninas, em que havia a presença de uma ou mais meninas e c) eventos mistos compostos por ambos, meninos e meninas. No total, foram registrados 202 eventos de meninos, o que representa $39 \%$ do total de eventos; 201 eventos de meninas representando também 39\%; e 114 eventos mistos, representando $22 \%$ dos eventos observados.

\section{Eventos de brincadeira quanto ao sexo das crianças versus tipos de brinquedos}

Foi verificada associação significativa entre os eventos de brincadeira quanto ao sexo das crianças e os tipos de brinquedos utilizados nesses eventos, ou seja, o tipo de brinquedo utilizado na brincadeira está associado ao sexo das crianças nela envolvidas. Com relação aos tipos de brinquedos, entre os meninos, o teste qui-quadrado evidenciou predominância pela utilização de jogos sociais $(37,6 \%)$, brinquedos que reproduzem o mundo técnico - carrinhos, helicópteros, robôs - $(17,2 \%)$ e fantasias $(15,2 \%)$ $\left(c^{2}=144,06 ; \mathrm{gl}=7 ; p<.001\right)$. Já entre as meninas, verificou-se a preferência por brinquedos responsáveis pelo desenvolvimento afetivo - pelúcias, bonecas, panelas - $(37,3 \%)$, seguido de jogos sociais (16\%) e fantasias $(14 \%)\left(c^{2}=141,96 ; g l=7 ; p<.001\right)$. Nos grupos mistos, verificou-se uma predominância da utilização dos jogos sociais $(29,8 \%)$, das fantasias $(21 \%)$ e dos brinquedos que reproduzem o mundo técnico $(16,8 \%)\left(\mathrm{c}^{2}=56,66\right.$; $\mathrm{gl}=7 ; p<.001)($ Tabela 1$)$. 
Tabela 1: Freqüências e porcentagens de utilização de cada tipo de brinquedo em função do sexo das crianças envolvidas no evento de brincadeira

\begin{tabular}{|c|c|c|c|c|c|c|}
\hline \multirow{3}{*}{$\begin{array}{c}\text { Classificação do brinquedo presente } \\
\text { no evento de brincadeira }\end{array}$} & \multicolumn{6}{|c|}{ Eventos de brincadeira quanto ao sexo das crianças } \\
\hline & \multicolumn{2}{|c|}{$\begin{array}{l}\text { Eventos de } \\
\text { meninos }\end{array}$} & \multicolumn{2}{|c|}{$\begin{array}{l}\text { Eventos de } \\
\text { meninas }\end{array}$} & \multicolumn{2}{|c|}{ Eventos mistos } \\
\hline & $f$ & $(\%)$ & $f$ & $(\%)$ & $f$ & $(\%)$ \\
\hline Atividades sensório-motoras & 10 & 5 & 21 & 10,4 & 10 & 8,8 \\
\hline Atividades físicas & 10 & 5 & 3 & 1,5 & 1 & 0,9 \\
\hline Atividades cognitivas & 16 & 8 & 22 & 10,9 & 9 & 7,9 \\
\hline Reprodução do mundo técnico & 35 & 17,2 & 15 & 7,4 & 19 & 16,8 \\
\hline Desenvolvimento afetivo & 8 & 4 & 75 & 37,3 & 6 & 5,2 \\
\hline Atividades criativas & 16 & 8 & 5 & 2,5 & 11 & 9,6 \\
\hline Jogos sociais & 76 & 37,6 & 32 & 16 & 34 & 29,8 \\
\hline Fantasia & 31 & 15,2 & 28 & 14 & 24 & 21 \\
\hline total & 202 & 100 & 201 & 100 & 114 & 100 \\
\hline
\end{tabular}

Eventos de brincadeira quanto ao sexo das crianças versus locais de eventos de brincadeira

Através do teste de associação qui-quadrado foi verificada associação significativa entre a composição do grupo de brincadeira quanto ao sexo das crianças e o local de evento de brincadeira na brinquedoteca $\left(\mathrm{c}^{2}=71,23 ; \mathrm{gl}=6 ; p<.001\right)$. Conforme pode ser visualizado na tabela 2 , os meninos, quandobrincam sozinhos ou entre si, têm preferência pelo tapete, enquanto que os grupos de meninas parecem não possuir uma única preferência, sendo que os dados indicam que a parede, o tapete e a mesinha são os locais mais utilizados por elas. Meninos e meninas, quando brincam juntos (eventos mistos), têm preferência pelo tapete (50\%), que é também o espaço preferido pelos meninos quando brincam entre si.

Tabela 2: Freqüências e porcentagens dos locais de ocorrência de eventos de brincadeira na brinquedoteca em função do sexo das crianças.

\begin{tabular}{l|cccccc}
\hline \multirow{2}{*}{$\begin{array}{l}\text { Local na } \\
\text { brinquedoteca }\end{array}$} & \multicolumn{5}{c}{ Eventos de brincadeira quanto ao sexo das crianças } \\
& \multicolumn{7}{c}{ Eventos de meninos } & Eventos de meninas & Eventos mistos \\
\cline { 2 - 7 } & $f$ & $(\%)$ & $f$ & $(\%)$ & $f$ & $(\%)$ \\
\hline Tapete & 127 & 62,8 & 54 & 26,8 & 57 & 50 \\
Parede & 19 & 9,4 & 65 & 32,4 & 10 & 8,8 \\
Mesinha & 33 & 16,4 & 49 & 24,4 & 27 & 23,7 \\
Canto da beleza & 23 & 11,4 & 33 & 16,4 & 20 & 17,5 \\
total & 202 & 100 & 201 & 100 & 114 & 100 \\
\hline
\end{tabular}

Ainda em relação ao local de evento de brincadeira, relacionou-se esta variável aos diversos tipos de brinquedos, sendo encontrada associação significativa entre estas duas variáveis $\left(\mathrm{c}^{2}=556,10 ; \mathrm{gl}=21 ; p<.001\right)$. Com base nesse dado, pode-se inferir que, na brinquedo- teca, determinadas brincadeiras ocorrem com maior freqüência em alguns locais. Com relação aos eventos observados no tapete, a maioria envolveu a utilização de jogos sociais (cinza - 44\%), seguido de brinquedos que reproduzem o mundo técnico (verde - 26,5\%). Dos 
eventos observados na parede, $75,6 \%$ envolveram brinquedos relacionados ao desenvolvimento afetivo (rosa). Nos eventos observados na mesinha, não houve um predomínio mais acentuado de um tipo de brinquedo. Por fim, nos eventos observados no canto da beleza predominou a utilização de fantasias (74\%).

\section{Presença de adultos}

Dos 517 eventos registrados, 135 deles ocorreram com um adulto por perto, ou seja, apenas $26 \%$ do total de eventos. Além disso, $46 \%$ da participação dos adultos nos eventos de brincadeira ocorreram com a presença de um brinquedo do tipo cinza - jogos que envolvem relações sociais. Essa presença era caracterizada, na maior parte do tempo, pelo auxílio e instrução do brinquedo, sendo pouco verificada o engajamento na atividade lúdica.

\section{DISCUSSÃO}

Este estudo teve como objetivo caracterizar os diferentes tipos de brinquedos utilizados em interações lúdicas de crianças com idades entre 6 e 8 anos em uma brinquedoteca e verificar possíveis diferenças de gênero existentes na brincadeira. Os resultados confirmaram a existência de segregação e estereotipia de gênero no brincar infantil. Foi evidenciado que meninos tendem a brincar entre si e meninas também. Nesse caso, a composição do grupo, de acordo com o sexo das crianças, determina o tipo de brinquedo utilizado na interação lúdica. Entre os grupos de meninos, foi verificada preferência pelos jogos sociais, brinquedos que reproduzem o mundo técnico - miniaturas, carrinho, helicópteros - e fantasias, respectivamente. Com relação aos grupos de meninas, constatou-se a predominância de utilização de brinquedos responsáveis pelo desenvolvimento afetivo - bonecas, bebês, roupinhas -, jogos soci- ais e fantasias, respectivamente. Nos grupos mistos, foi verificada preferência pelos jogos sociais, fantasia e brinquedos que reproduzem o mundo técnico, respectivamente.

\section{Segregação}

Com relação à segregação entre os sexos na brincadeira constatada neste estudo, encontrou-se consistência com outras pesquisas $^{7,9,23,25}$, as quais também verificaram que as crianças demonstram preferência por parceiros de mesmo sexo nas interações lúdicas. Segundo Bjorklund e Pellegrini ${ }^{9}$, próximo aos 6 e 7 anos de idade, as crianças já apresentam um conhecimento sobre as atividades, papéis sexuais e objetos sexualmente tipificados e brincam de maneira segregada. Essa forma de brincar, de acordo com Liss ${ }^{24}$, faz com que meninos e meninas socializem-se dentro de mundos diferentes e adquiram habilidades distintas. Martin e Fabes ${ }^{34}$ sugerem que a segregação por sexo afeta o desenvolvimento das crianças, canalizando interesses e experiências e limitando os tipos de atividades nas quais se envolvem e que, quanto mais elas se expõem a pares do mesmo sexo, mais seus comportamentos se tornam sexualmente diferenciados.

Muitas das explicações para a preferência por brincar com crianças do mesmo sexo dizem respeito à semelhança das atividades preferidas por elas ${ }^{35}$. Martin e Fabes ${ }^{34}$ propõem, como uma das explicações para a segregação sexual, a compatibilidade comportamental entre as crianças. Por exemplo, meninos muito ativos procurariam companheiros igualmente ativos: presumivelmente, outros meninos.

\section{Estereotipia}

A estereotipia na brincadeira foi verificada tanto nos grupos de meninos quanto de meninas, uma vez que ambos demonstraram preferências tanto em relação ao brinquedo quan- 
to ao local de brincadeira. Estes resultados estão em conformidade com outros estudos, realizadas com crianças de várias idades, os quais mostraram que os meninos brincam mais com brinquedos masculinos, enquanto as meninas preferem os brinquedos femininos ${ }^{17,18,19}$. No entanto, foi constatado que meninos tendem a brincar de forma mais estereotipada que meninas em relação ao local de brincadeira na brinquedoteca e em relação aos brinquedos; dados que se encontram de acordo com outras pesquisas $^{7,19,20}$. Segundo Cordazzo $^{7}$ (p.65), “a idade ápice para a segregação dos sexos nas brincadeiras está entre os 6 e 8 anos de idade e os meninos têm uma maior tendência para esta segregação e estereotipia".

Através das observações, foi verificado que os meninos possuem maior preferência por três tipos de brinquedos apenas (jogos sociais, brinquedos que reproduzem o mundo técnico e fantasias). Apesar de os jogos sociais terem prevalecido entre as brincadeiras dos meninos, verificou-se também grande procura por brinquedos que reproduzem o mundo técnico. Alguns autores, como Porto ${ }^{15}$ e Bichara ${ }^{16}$, afirmam que meninos possuem preferência por brinquedos que reproduzem o universo externo e do trabalho como brincadeiras de super-herói, papéis com muita ação e transportes. A fim de buscar uma possível explicação do predomínio das brincadeiras de meninos com os jogos sociais, percebeu-se que estes estavam, em sua maioria, também relacionados ao mundo externo (jogos que envolvem estratégia, guerra, selva) e ao trabalho (profissões, banco, mercado, transportes).

Os brinquedos mais utilizados nas brincadeiras de meninas nesta pesquisa foram aqueles relacionados ao desenvolvimento afetivo. No entanto, foi verificado que as meninas utilizaram também vários outros tipos de brinquedos. Nesse sentido, conclui-se que as meninas brincaram de forma menos estereotipada em relação aos brinquedos. Dentre os mais procurados, verifi- cou-se a presença de objetos lúdicos associados ao brincar de casinha, como roupinhas, boneca, berço, carro de supermercado, fogão, bebê, bolsa e pelúcias. Pesquisas indicam que o espaço familiar da casa é associado às meninas e que elas procuram brincadeiras mais realísticas que imitam a vida real, como atividades domésticas, casamentos e festas ${ }^{15,16}$.

Quanto à estereotipia relacionada ao local de brincadeira, foi verificado que os meninos mostraram preferir brincar mais no tapete, enquanto que as meninas pareceram não possuir uma única preferência, sendo que os dados indicaram que a parede, o tapete e a mesinha foram os locais mais utilizados por elas. Uma possível explicação é a de que o tapete seria o local propício para as brincadeiras que envolvem jogos sociais, mais utilizados pelos meninos, sendo que não há naquela brinquedoteca um outro local adequado para este fim.

Diversos pesquisadores têm se dedicado a identificar diferenças de gênero no comportamento das crianças ${ }^{7,19,20,25}$. Uma possível explicação para essas diferenças manifestadas na brincadeira poderia estar baseada em uma abordagem biológica que afirma que os homens são por natureza diferentes das mulheres ${ }^{36}$. Outra abordagem, mais voltada para o social, argumenta que os pais e outros adultos encorajam comportamentos e interesses na criança que confirmam suas próprias visões de comportamentos estereotipados ${ }^{37}$.

Uma explicação mais pertinente para as diferenças de gênero no comportamento infantil, na qual o presente estudo se baseia, é trazida pela perspectiva interacionista do desenvolvimento humano. Tal abordagem considera que os aspectos biológico e ambiental/cultural atuam de forma interdependente na determinação do comportamento humano ${ }^{38}$. A partir desta perspectiva, o comportamento parental agiria de forma a fortalecer (e algumas vezes modificar) predisposições biológicas já existentes. Diante disso, a criança já nasceria com deter- 
minadas predisposições relacionadas às diferenças entre os gêneros, que seriam fortalecidas ou não pela influência dos pais.

\section{Brinquedoteca}

Com relação à brinquedoteca, verificase que poucos estudos empíricos foram realizados visando caracterizar as brincadeiras de crianças nestes espaços. A brinquedoteca contribui para o desenvolvimento infantil com as diversas atividades lúdicas, individuais e coletivas, que ela possibilita a criança. Constitui-se em um lugar propício para observar e conhecer de forma mais completa a criança e suas interações lúdicas ${ }^{39}$. O mobiliário de uma brinquedoteca é arrumado de forma a constituir ambientes propícios para o desenrolar de atividades específicas ${ }^{15}$. Na brinquedoteca em estudo, existem alguns cantinhos de brincar como o espaço da casinha, o canto da beleza, o tapete e a mesinha. Através desta pesquisa, foi possível confirmar que determinadas brincadeiras ocorrem com maior frequiência em alguns destes locais da brinquedoteca.

A brinquedoteca é capaz de propiciar uma grande variedade de brincadeiras entre as crianças, permitindo uma revalorização da dimensão lúdica e dando-lhe a devida importância ${ }^{15}$. Através deste estudo, constatou-se que a brinquedoteca é capaz de propiciar brincadeiras que, em outros contextos, não estariam surgindo. A brincadeira de faz-de-conta mediada pelas fantasias, verificada nas brincadeiras de meninas, de meninos e também nos grupos mistos, seria um exemplo de um tipo de brincadeira que a brinquedoteca é capaz de propiciar em função da variedade de objetos e fantasias que ela possui em seu mobiliário e que estão relacionados com este tipo de brincadeira.

\section{Papel do adulto na brincadeira}

Com relação à presença de adultos nas interações lúdicas dentro da brinquedoteca, verificou-se que estes nem sempre estão presentes atuando de forma a mediar o brincar infantil. O papel do adulto na brincadeira seria o de organizar o espaço, selecionar os brinquedos e interagir com as crianças, desde que não entre em conflito com a ação voluntária da criança ${ }^{40}$. No caso da brinquedoteca, que já possui seu espaço organizado de forma a propiciar uma ampla variedade de brincadeiras, o papel do adulto seria instruir, interagir com as crianças, disponibilizar brinquedos e, como citam Martins, Vieira e Oliveira ${ }^{41}$, selecionar papéis durante a brincadeira de faz de conta, entre outros. Um outro dado, relacionado à presença de adultos na brincadeira, é o de que quase metade de suas participações nas interações lúdicas esteve relacionada com a utilização de jogos sociais. Diante disso, pode-se dizer que os adultos possuem uma tendência para instruir e auxiliar as crianças nas atividades, sendo pouco verificado seu engajamento em brincadeiras que envolvam o faz-de-conta, por exemplo.

\section{CONSIDERAÇÕES FINAIS}

O tema aqui investigado possui diversas implicações dado ser possível que diferentes brinquedos utilizados na infância propiciam desenvolvimentos sociais e cognitivos diversos. As diferenças no brincar de meninos e meninas podem encorajá-los a desenvolver diferentes interesses e maneiras de se relacionar com o mundo ${ }^{42}$. Estudos a esse respeito são importantes, seja para fornecer uma melhor compreensão da criança atual ou projetar um melhor entendimento das sociedades futuras, pois o tipo de contato e atividades que a criança desenvolve hoje terá influência na adaptação do homem de amanhã.

Nesta pesquisa foi constatado que a criança em idade escolar possui forte motivação para a brincadeira. A fim de cercar outros aspectos que envolvem o brincar infantil, suge- 
rem-se novas pesquisas que utilizem o método de observação por sujeito focal, para assim serem verificadas as preferências individuais das crianças. A observação de variáveis como o tempo de permanência da criança com o brinquedo, o número de brinquedos e par- ceiros com os quais ela brinca, o sexo desses parceiros e a natureza da brincadeira (faz-deconta, turbulenta ou realística) podem ser consideradas outras características importantes a serem investigadas acerca das crianças e suas brincadeiras.

\begin{abstract}
The present research aimed to characterize schoolchildren's play behavior in a toy library, identifying the different toys used by boys and girls during their play. 517 direct observations of free play events were performed, using an observational protocol. The results confirmed the existence of segregation and stereotypes in children's play, showing that boys tend to play with boys and girls, with girls. Furthermore, the composition of the group, based on the sex of the children, determines the type of toy used in the playing activity. The groups of boys showed preference for social games, toys that reproduce the technical world - miniatures, little cars, helicopters - and fantasies. In the groups of girls, toys which are related to affective development - dolls, babies, dolls' clothes -, social games and fantasies prevailed. In the mixed groups, a predominance of the use of social games, fantasies and toys that reproduce the technical world was verified. The variety of playing activities verified in this research can be explained by the great collection of toys and possibilities of creations offered by the toy library and its playing spaces.
\end{abstract}

Key-words: play, toy library, gender.

\section{REFERENCIAS}

1. Fantin M. No mundo da brincadeira: jogo, brinquedo, e cultura na educação infantil. Florianópolis: Cidade Futura; 2000.

2. Pellegrini AD, Smith PK. Physical activity play: the nature and function of a neglected aspect of play. Child Dev. 1998;69(30):577-98.

3. Kishimoto TM, organizador. O brincar e suas teorias. São Paulo: Pioneira; 1988.

4. Moraes AS. Análise estrutural e funcional da brincadeira de crianças em idade pré-escolar [dissertação]. Florianópolis: Universidade Federal de Santa Catarina; 2001.

5. Souza A, Vieira ML. Origens históricas da brincadeira. Psicol Bras. 2004;2(7):28-33.

6. Dohme V. Atividades lúdicas na educação: o caminho de tijolos amarelos do aprendizado. Petrópolis: Vozes; 2003.

7. Cordazzo STD. Caracterização de brincadeiras de crianças em idade escolar [dissertação]. Florianópolis: Universidade Federal de Santa Catarina; 2003.

8. Lopes MG. Jogos na educação: criar, fazer, jogar. $3^{\text {a }}$ ed. São Paulo: Cortez; 2000.
9. Bjorklund DF, Pellegrini AD. Child development and evolutionary psychology. Child Dev. 2000;71(6):1687-708.

10. McHale SM, Crouter AC, Tucker CJ. Family context and gender role socialization in middle childhood: comparing girls to boys and sisters to brothers. Child Dev. 1999;70(4):990-1004.

11. Humphreys AP, Smith EK. Rough-and-tumble in preschool and playground. In: Smith PD, editor. Play in animals and humans. Oxford: Blackwell; 1984. p. 241-66.

12. Beraldo KEA. Gênero de brincadeiras na percepção de crianças de 5 a 10 anos [dissertação].

São Paulo: Instituto de Psicologia da Universidade de São Paulo; 1993.

13. Maccoby EE, Jacklin CN. The psychology of sex differences. Stanford (CA): Stanford University Press; 1974.

14. Lindsey EW, Mize J. Contextual differences in parent-child play: implications for children's gender role development. Sex Roles. 2001;44(34):155-76.

15. Porto CL. Brinquedo e brincadeira na brinquedoteca. In: Kramer S, Leite MI, organizadores. Infância e produção cultural. Campinas: Papirus; 1998. p. 171-98.

16. Bichara ID. Um estudo etológico da brincadeira 
de faz-de-conta em crianças de 3-7 anos [tese]. São Paulo: Instituto de Psicologia da Universidade de São Paulo; 1994.

17. Knickmeyer RC, Wheelwright S, Taylor K, Raggatt P, Hackett G, Baron-Cohen S. Gendertyped play and amniotic testosterone. Dev Psychol. 2005;41(3):517-28.

18. Lindahl LB, Heimann M, Balheden S. Connections between degree of social proximity and gender typed play in motherinfant interactions. Göteborg Psychol Rep. 1997;27(11):1-12.

19. Servin A, Bohlin G, Berlin L. Sex differences in 1-, 3- and 5-year-olds 'toy-choice in a structured play session. Scand J Psychol. 1999;40(1):43-8.

20. Morais MLS. Conflitos e $(\mathrm{m})$ brincadeiras infantis: diferenças culturais e de gênero [tese]. São Paulo: Instituto de Psicologia da Universidade de São Paulo; 2004.

21. Signorella ML, Bigler RS, Liben LS. Developmental differences in children's gender schemata about others: a meta-analytic review. Dev Rev. 1993;13(2):147-83.

22. Poulin-Dubois D, Serbin LA, Eichstedt JA, Sen MG, Beissel CF. Men don't put on make-up: toddlers' knowledge of the gender stereotyping of household activities. Soc Dev. 2002;11(2):165-81.

23. Martin CL, Fabes RA, Evans SM, Wyman H. Social cognition on the playground: children's beliefs about playing with girls versus boys and their relations to sex segregated play. J Soc Pers Relat. 1999;16(6):751-71.

24. Liss MB. Social and cognitive skills: sex-roles and children's play. New York (NY): Academic Press; 1983. Learning gender-related skills through play; p. 147-67.

25. Fabes RA, Martin CL, Hanish LD. Young children's play qualities in same-, other-, and mixed-sex peer groups. Child Dev. 2003;74(3):921-32.

26. Hinde RA. Individuals, relationships and culture: links between ethology and social sciences. Cambridge (UK): Cambridge University Press; 1987.

27. Maccoby EE. Gender as a social category. Dev Psychol. 1988;24(6):755-65.

28. Rabinovich EP. Nos tempos dos avós. In: Carvalho AMA, Magalhães CMC, Pontes FAR,
Bichara ID, organizadores. Brincadeira e cultura: viajando pelo Brasil que brinca. São Paulo: Casa do Psicólogo; 2003. p. 9-30.

29. Kishimoto TM. Diferentes tipos de brinquedotecas. In: Friedmann A, organizador. O direito de brincar. $4^{\mathrm{a}}$ ed. São Paulo: Ed. Sociais; 1998. p. 49-59.

30. Michelet A. Classificação dos jogos e brinquedos: a classificação ICCP. In: Friedmann A, organizador. O direito de brincar. $4^{a}$ ed. São Paulo: Ed. Sociais; 1998. p. 161-72.

31. Fagundes AJFM. Descrição, definição e registro de comportamento. $12^{a}$ ed. São Paulo: Edicon; 1999.

32. Pellegrini AD. Observing children in their natural world: a methodological primer. New Jersey: Erlbaum; 1996.

33. Kail RV. A criança. São Paulo: Prentice Hall; 2004.

34. Martin CL, Fabes RA. The stability and consequences of young children's same-sex peer interactions. Dev Psychol. 2001;37(3):431- 46.

35. Maccoby EE. Peer conflict and intrafamily conflict: are there conceptual bridges? Merrill Palmer Q. 1996;42(1):165-76.

36. Hanser H. Diferentes desde o nascimento. Viver Mente Cérebro. 2005;146(8):32-9.

37. Etaugh C, Liss MB. Home, school, and playroom: training grounds for adults gender roles. Sex roles. 1992;26(3-4):129-47.

38. Bussab VSR. Fatores hereditários e ambientais no desenvolvimento: a adoção de uma perspectiva interacionista. Psicol Reflex Crít. 2000;13(2):233-43.

39. Bomtempo E. Brinquedoteca: espaço de observação da criança e do brinquedo. In: Friedmann A, organizador. O direito de brincar. $4^{a}$ ed. São Paulo: Ed. Sociais; 1992. p. 77-82.

40. Kishimoto TM. O jogo na educação infantil. $3^{\text {a }}$ ed. São Paulo: Pioneira; 1994.

41. Martins GDF, Vieira ML, Oliveira AMF. O olhar de professores sobre o brincar na pré-escola. In: Anais do V Congresso Brasileiro de Psicologia do Desenvolvimento; 2005 Set 8-10; São Paulo, Brasil. Florianópolis: UFSC; 2005. p. 139.

42. Miller CL. Qualitatives differences among gender-stereotyped toys: implications for cognitive and social development in girls and boys. Sex Roles. 1987;16(9-10):473-87. 